\title{
Fossil Crabs dredged from the Bottom of Tosa Bay:
}

\author{
Hiroshi Nuno.
}

Large blocks of nodules were dredged by the surveying ship Sôyômaru at the station $221,33^{\circ} 20^{\prime} 30^{\prime \prime} \mathrm{N}, 135^{\circ} 50^{\prime} 00^{\prime \prime} \mathrm{E}$, about three miles off Muroto Peninsula, Prov. Tosa, at a depth of 209 meters and were put at my disposal through the kindness of the director of the Imperial Fisheries Experimental Station.

On breaking one of these hard nodules, many fragments of fossil crab and mollusk were obtained. The specimens of fossil crabs consist of one carapace; right half of a body comprising carapace, abdomen, cheliped and an ambulatory leg; a fragment with an arm and first leg; two palms; and many fragments of ambulatory legs.

They are undoubtedly referable to one species and capable of being described under the following one series of headings.

Carapace: Subovate in outline, one and half times wider than long, with moderate convexity antero-posterioly, much slighter curvature, surface evenly granulate; three insignificant teeth including the orbital tooth and lateral spine present on each of the antero-lateral borders. Lateral spine conical, but not so prominent. Orbital tooth largest of all, directed forward. Frontal wavy, slightly concave, both sides a little produced; its breadth about one foüth the length of the carapace. Orbital cavity is relatively large and far apart from each other. Cheliped: Palm rectangular, breadth is about one third of length; proximal margin undulating, its lower and upper corners with two prominent counded lobes, lower margin nearly straight; inner surface slightly ridged, with a conical projection at the distal one third. Propodal finger slightly shorter than palm, a little concave on inner surface, ending in a sharp recurved spine; triangular prehensile teeth interspersed with three or four smaller ones. Dactyl finger very thick, broader than the opposite one, curved downward, pointed at tip ; upper border rounded, outer surface convex but inner surface slightly concave; of the three large teeth on its lower border, the proximal one the largest, two smaller teeth between each two larger ones. Carpus: Subquadrate in outline; short, not exceeding one half the length of the manus; an acute small spine at outer angle, and a large spine at inner angle. Merus : Large and triangular in shape, as long as propodus and very narrow at the proximal articulation, lower margin moderately convex distally; outer surface divided into upper and lower flat halves by a distinct longitudinal median ridge, which has an acute spine at distal one-third and a conical spine on the distral end of lower margin. Ischium: Triangularly shaped, 


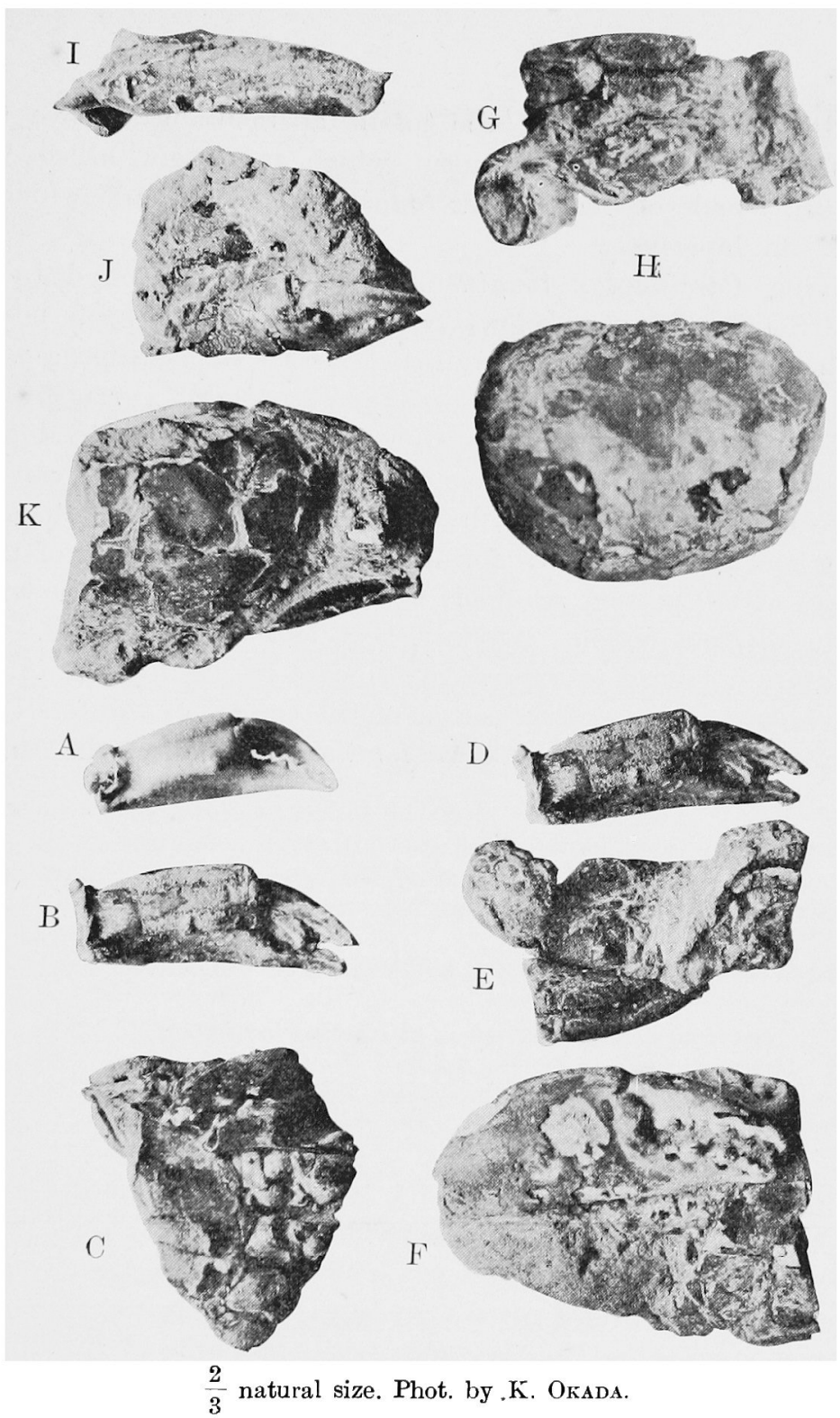

A, Cheliped of living Carcinoplax longimanus de Haan; B, Cheliped of the fossil crab; C, Abdomen of the fossil crab; D, Cheliped of the fossil crab; $\mathrm{E}$, fragment with an arm and first leg (onter view); F, Ventral view. Right half of a body consisting of carapace, abdomen, cheliped and an ambulatory leg; G, fragment with an arm and first leg (inner view); H, Carapace; I, Merus; J, Cheliped; $\mathbf{K}$, Dorsal view. Right half of a body consisting of carapace, abdomen, cheliped and an ambulatory leg. 
very small and compressed.

From the characteristics of the fossils as mentioned above the writer considers that they represent a form which is closely allied to, if not identical with, female of Carcinoplax longimanus (de Haan)* which is called "Enkôgani" in Japanese.

The living Carcinoplax longimanus (de Haan) is found in Formosa, Central and Southern Japan, below the sea level. In the same nodule which contained the remains of the fossil crab, two species of gastropoda were found, viz., Olivella spretoides Yok. and Turris granosa Hebl. Turris granosa Hebl. is living in adjacent sea where the nodule was found, while Olivella spretoides Yok. is found in the fossil bed of Narita series (Pleistocene). I can not decide between two alternatives whether the nodule which contained those remains of the crabs and gastropoda was formed by the consolidation of the present living species at the present sea-floor, or it was derived from the tertiary rock developed in adjacent region. Anyway, they look well fossilized.

In conclusion I wish to express my sincere thanks to Prof. A. Terao for his kind guidance in the determination of the species of the fossil crab and I am also grateful to Mr. H. Marukawa for the collection of the sample.

* Cancer (Curtonotus) longimanus. de Hans, Fauna Japon., Crust, 1835, p. 50, pl. vi. fig. 1. Carcinoplax longimanus. Alcock: Jour. Asiatic Soc. Bengal. 69, 1900, p. 303.; Mary J. RATHbun: Proe. U. S. Nat. Mus. 26, 1902, p. 23. 